\title{
Learning Curve for Laparoscopic Hysterectomy: An Experience from Kathmandu University Hospital
}

\author{
Suman Raj Tamrakar, Pradhan N, Suresh Kayastha \\ Department of Obstetrics and Gynecology, Dhulikhel Hospital - Kathmandu University Hospital, Kavre
}

Received: 20 November 2018; Accepted: 12 December 2018

DOI: 10.3126/njog.v13i3.23427

\begin{abstract}
Aims: The aim of this study is to assess learning curves for laparoscopic hysterectomies, compare the performance of surgeons and review demographic parameters of the patients, varieties of complications experienced and indications of the procedures

Methods: A retrospective study was conducted in Kathmandu University Hospital, Kavre of January 1, 2011 to June 30, 2018.

Results: A total of 1849 cases were already performed by mid 2018. Of them, 261 (14.12\%) cases were LAVH and TLH cases. Mean duration for laparoscopic hysterectomies (for both LAVH and TLH) was $142.21 \pm 43.46$ minutes (range 55 to 310 minutes) and one third of the cases performed in a range of 121 to 150 minutes. There is difference in mean duration of operation between surgeons which is statistically significant $(\mathrm{p}<0.001)$. Beside one of four surgeons (surgeon B) had significant reduction in mean duration for LAVH surgery $(\mathrm{p}=0.004)$. Same surgeon has significant reduction in mean duration for performing TLH ( $\mathrm{p}=0.0047)$. Of the 261 laparoscopic hysterectomies, 8 cases $(3.07 \%)$ turned into laparotomy
\end{abstract}

Conclusions: Laparoscopic hysterectomies are feasible with reducing mean operating time across the period. These minimal invasive surgeries are safe with low rate of complications and less conversion to open even in our set up.

Keywords: hysterectomy, laparoscopy, learning curve.

\section{INTRODUCTION}

Hysterectomy is the most frequently performed major gynecologic surgery, mostly for uterine pathologies. Minimal invasive approach is preferred whenever the criteria are met ${ }^{1,2}$ In comparison to open surgery, laparoscopic procedures have many benefits. ${ }^{3}$ But surgeons need advance surgical skills to perform laparoscopic surgery. The acquisition of this technical skill is represented by a learning curve. ${ }^{4}$ Though the number of cases needed to achieve criterion-level performance ranges from 20 to 30 , the criteria used for defining the competence can vary between studies. ${ }^{5}$

There are few publications related to experiences of laparoscopic hysterectomies from Nepal. ${ }^{6-8}$ But there are no studies on learning curves for laparoscopic hysterectomies. Dhulikhel Hospital (DH) or Kathmandu University Hospital (KUH) has started laparoscopic hysterectomy services since 2011. Since then these surgeries are being regularly performed. In recent days, it is being most frequently

\section{CORRESPONDENCE}

Dr Suman Raj Tamrakar

Department of Obstetrics and Gynecology,

Dhulikhel Hospital Kathmandu University Hospital, School of

Medical Sciences (KUSMS), Dhulikhel, Kavre

Phone: +977-9843530450

Email: drsuman3947@gmail.com performed gynecologic surgery. The aim of this study is to assess learning curves for laparoscopic assisted vaginal hysterectomy (LAVH) and total laparoscopic hysterectomy (TLH) and to compare the performance of surgeons involving in these surgeries. Beside, demographic parameters of the patients, varieties of complications experienced and indications of the procedures, will also analyzed as part of this study. The study findings will be informative to the aspirants of gaining knowledge in laparoscopic gynecologic field.

\section{METHODS}

This retrospective comparative study was conducted in Kathmandu University Hospital, Kavre. Laparoscopic gynecological surgeries are being regularly performed in KUH since few years. Data were obtained from the patients who underwent laparoscopic hysterectomies were included in the study. Data were retrieved from OPD/inpatient and Operation Theatre (OT) records of January 1, 2011 to June 30, 2018. Certain 
socio-demographic information namely caste, age, address and co-morbid condition of the patients were analyzed.

For reviewing learning curve for LAVH or TLH and the performance of laparoscopic surgeons, primary gynecological surgeons were divided into four groups. Names of these surgeons were kept confidential. Mean duration of the surgeries performed by each laparoscopic surgeon along with statistical difference in performing initial and last $15 \mathrm{LAVH}$ cases were calculated. That of TLH was analyzed in initial and last ten cases; and among three surgeons only. One of the surgeons had not performed the adequate numbers of TLH. TLH cases were extensively performed from mid 2017. Ethical clearance was taken from the hospital research committee prior to data collection. All data were analyzed by SPSS 16 packages using appropriate statistical tools.

\section{RESULTS}

\section{Demography}

Most of the cases were of Brahmin/Chhetri (55.2\%, 144), Newar $(25.7 \%, 67)$, Other Janajati (mostly Tamang $10.7 \%)$, Lower caste $(6.9 \%, 18)$ and Madhesi $(1.5 \%, 4)$. But this caste distribution was different than that of State number 3 of Nepal, which is primarily catchment of KUH. Caste distribution of State 3 is Brahmin/Chhetri (35.56\%), Newar (16.92\%), and Other Janajati (25.31\%). This may be due to health seeking behavior and affordability of the clients. Mean age of the patient was $46.48 \pm 5.89$ years (with range $30-71$ years). Most of them were age group of 41-50 years $(62.5 \%)$ followed by $31-40$ years $(18 \%), 51-60$ years $(16.5 \%)$ and above $(3.1 \%)$. Half of the patients were from Kavre (50.2\%), followed by Kathmandu valley (particularly Bhaktapur) (28.1\%), neighboring districts like Sindhu Patchwork, Dolakha, Ramechhap, Sindhuli (13\%) and other districts (7.7\%).

\section{Co-morbid condition}

And 97 patients were presented with additional medical problems (diabetes, hypertension, hypothyroidism, depression, anemia, cholecystolithiasis, dyslipidemia etc.) or double gynecological pathology. Laparoscopic cholecystectomy (10 cases), pelvic floor repair ( 9 cases), adhesiolysis (4 cases), transvaginal taping (one case) and laparoscopic appendectomy (one case) were performed along with LAVH or TLH. It took little longer duration than mean operation duration (142.21 \pm 43.46 minutes) for operating these 97 cases. There was year-wise increment in laparoscopic hysterectomy cases in KUH, noticeably from 2016.

The indications for performing LAVH or TLH were tabulated (Table 1).

Table 1: Indication of laparoscopic hysterectomies $(n=261)$.

\begin{tabular}{|l|l|l|}
\hline \multicolumn{1}{|c|}{ Indication } & Frequency & Percent \\
\hline Fibroid & 94 & 36.0 \\
\hline Abnormal uterine bleeding & 72 & 27.6 \\
\hline $\begin{array}{l}\text { Pathology in Uterus } \\
\text { (other than fibroid and } \\
\text { premalignant condition) }\end{array}$ & 43 & 16.5 \\
\hline Chronic pelvic pain & 16 & 6.1 \\
\hline Premalignant condition & 16 & 6.1 \\
\hline Pathology in ovary & 11 & 4.2 \\
\hline UV prolapse & 9 & 3.4 \\
\hline
\end{tabular}

Mean duration for laparoscopic hysterectomies (for both LAVH and TLH) was $142.21 \pm 43.46$ minutes (range 55 to 310 minutes) and one third of the cases performed in a range of 121 to 150 minutes (Table 2).

Table 2: Range of laparoscopic hysterectomies(n=261).

\begin{tabular}{|l|l|l|}
\hline OT duration (in minutes) & Frequency & Percent \\
\hline $61-90$ & 21 & 8.0 \\
\hline $91-120$ & 71 & 27.2 \\
\hline $121-150$ & 82 & 31.4 \\
\hline $151-180$ & 41 & 15.7 \\
\hline $181-210$ & 24 & 9.2 \\
\hline $211-240$ & 14 & 5.4 \\
\hline 241 above & 8 & 3.1 \\
\hline & & \\
\hline
\end{tabular}

All surgeons reduced the operating duration of laparoscopic hysterectomies (Figure 1).

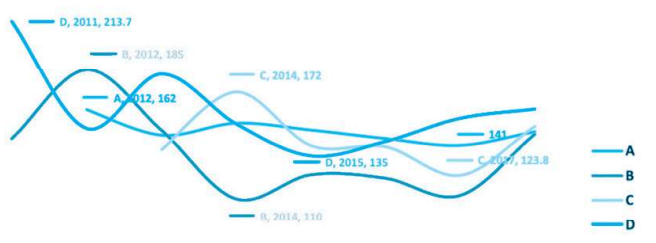

Figure 1: Year-wise mean duration of laparoscopic hysterectomies depending upon the surgeons. 
There is difference in mean duration of operation between surgeons which is statistically significant $(p<0.001)$ [Table-3]. Beside one of four surgeons (surgeon B) had significant reduction in mean duration for LAVH surgery $(p=0.004)$ [Table-4]. Same surgeon has significant reduction in mean duration for performing TLH ( $\mathrm{p}=0.0047)$ [Table-5].

Table 3: Comparison of mean duration of overall laparoscopic hysterectomies depending upon the surgeons.

\begin{tabular}{|c|c|c|c|}
\hline Surgeon & & Statistic & p value \\
\hline & Mean & 145.90 & \multirow{12}{*}{0.001} \\
\hline & $\begin{array}{l}95 \% \text { Confidence } \\
\text { Interval for }\end{array}$ & $135.12-156.69$ & \\
\hline & Std. Deviation & 46.228 & \\
\hline \multirow[t]{3}{*}{ B } & Mean & 126.60 & \\
\hline & $\begin{array}{l}95 \% \text { Confidence } \\
\text { Interval }\end{array}$ & $117.30-135.90$ & \\
\hline & Std. Deviation & 39.857 & \\
\hline \multirow[t]{3}{*}{$\mathrm{C}$} & Mean & 141.38 & \\
\hline & $\begin{array}{l}95 \% \text { Confidence } \\
\text { Interval for Mean }\end{array}$ & $132.37-150.39$ & \\
\hline & Std. Deviation & 38.059 & \\
\hline \multirow[t]{3}{*}{$\mathrm{D}$} & Mean & 163.32 & \\
\hline & $\begin{array}{l}95 \% \text { Confidence } \\
\text { Interval }\end{array}$ & $149.96-176.68$ & \\
\hline & Std. Deviation & 43.943 & \\
\hline
\end{tabular}

Table 4: LAVH - comparison of first and last 15 surgeries among the surgeons.

\begin{tabular}{|l|l|l|l|l|}
\hline Surgeon & Surgeries & Mean & $\begin{array}{l}\text { Std. } \\
\text { Deviation }\end{array}$ & $\begin{array}{l}\text { P } \\
\text { value }\end{array}$ \\
\hline \multirow{2}{*}{ A } & FIRST 15 & 152.67 & 20.948 & 0.14 \\
\cline { 2 - 4 } & LAST 15 & 132.27 & 47.659 & \\
\hline \multirow{2}{*}{ B } & FIRST 15 & 140.00 & 50.214 & \multirow{2}{*}{0.045} \\
\cline { 2 - 4 } & LAST 15 & 111.13 & 17.928 & \\
\hline C & FIRST 15 & 145.33 & 32.319 & \multirow{2}{*}{0.24} \\
\cline { 2 - 4 } & LAST 15 & 127.73 & 47.831 & \\
\hline \multirow{2}{*}{ D } & FIRST 15 & 175.53 & 45.190 & \multirow{2}{*}{0.44} \\
\cline { 2 - 4 } & LAST 15 & 162.20 & 49.883 & \\
\hline
\end{tabular}

Table 5: TLH - comparison of first and last 10 surgeries among the surgeons.

\begin{tabular}{|l|l|l|l|l|}
\hline Surgeon & Surgeries & Mean & $\begin{array}{l}\text { Std. } \\
\text { Deviation }\end{array}$ & \multirow{2}{*}{ P value } \\
\hline \multirow{2}{*}{ A } & FIRST 10 & 148.00 & 53.992 & 0.69 \\
\cline { 2 - 4 } & LAST 10 & 140.70 & 21.040 & \\
\hline \multirow{2}{*}{ B } & FIRST 10 & 136.67 & 26.637 & 0.047 \\
\cline { 2 - 4 } & LAST 10 & 110.00 & 12.247 & \\
\hline \multirow{2}{*}{ C } & $\begin{array}{l}\text { FIRST- } \\
10\end{array}$ & 129.70 & 34.973 & 0.124 \\
\cline { 2 - 4 } & LAST -10 & 155.00 & 35.119 & \\
\hline
\end{tabular}

\section{DISCUSSION}

Minimal invasive approach is preferred for hysterectomy whenever the criteria are met ${ }^{1,2}$ Reich $^{9}$ created new history performing the first laparoscopicassisted vaginal hysterectomy (LAVH), Since then the laparoscopic hysterectomies have been perceived as an alternative to conventional hysterectomy with various advantages. ${ }^{10}$ In LAVH, any portion of surgery performed laparoscopically with the majority performed vaginally but TLH is completely performed laparoscopically, including dividing uterine arteries, suturing of the vaginal cuff or other combinations. ${ }^{11}$

Despite the introduction of laparoscopic-assisted hysterectomies in the developed countries long time back, most surgeons in those countries still conducting in conventional ways..$^{9,12,13}$ So, introducing laparoscopic hysterectomies in developing countries like Nepal, yet could be big challenge. In KUH, most of the gynecologic surgeries are being performed thorough minimal approach.

Minimally invasive gynecological surgeries were being regularly performed in KUH since 2004. A total of 1849 cases were already performed by mid 2018 . Of them, 261 (14.12\%) cases were LAVH and TLH, rest were hysteroscopy $(41.6 \%, 769)$, diagnostic laparoscopy $(14.6 \%, 270)$, diagnostic laparoscopic with chromotubation $(6.2 \%, 111)$, and laparoscopic procedures (except hysterectomies) (21.63\%, $400)$. And 34 cases (1.8\%) were converted to open (laparotomy) for certain reasons (Tamrakar SR, 2018, unpublished data).

A survey of Australian gynecologists showed the majority $(77.4 \%)$ would like to increase their ability to learn less-invasive hysterectomy approaches and offer this option to their patients. ${ }^{14}$ The major challenge for the initiation of laparoscopic surgery is the difficulty for surgeons to acquire the necessary advanced laparoscopic surgical skills. ${ }^{15}$ And the learning period may increase the risk of complications. 16 The learning curve permits the description of one's capability to adopt new skills and technique on a time and quality-based scale. ${ }^{17}$

In a study ( $\mathrm{n}=88 \mathrm{LAVHs}$ ) by Shwayder ${ }^{18}$ found that the learning curve was relatively short with the most rapid operating time and complexities encountered within the first 20 cases. Similar experience has been shown by Mavrova R et al. ${ }^{19}$ They found duration 
of surgery for all surgeons decreased from $136 \pm 60$ minutes to $118 \pm 44$ minutes after 20 TLH procedures. And experienced surgeons have a steeper learning curve than do their inexperienced counterparts.

The average operating time was 121 minutes. ${ }^{18}$ In a two phase study by Wattiez et $\mathrm{al}^{20}$ operating times of 115 minutes (40-270 $\mathrm{min}$ ) reduced to 90 minutes (40$180 \mathrm{~min})(\mathrm{p}<0.005)$. The overall mean duration of laparoscopic hysterectomies is $142.21 \pm 43.46$ minutes (range 55 to 310 minutes) in our study. We have also experienced the reduction in operating time after 15 to 20 cases.

Hysterectomy is the most frequently performed for uterine pathologies. ${ }^{1,2}$ Agarwal et $\mathrm{al}^{21}$ showed most common indications for TLH were uterine myoma followed by abnormal uterine bleeding and endometrial hyperplasia. We have also experienced same (Table 1). Timothy et $\mathrm{al}^{22}$ reported that the most common indication of TLH was adenomyosis. Obesity and big uteri are not a contraindication for that minimally-invasive access. ${ }^{23}$ We have also performed large numbers of laparoscopic hysterectomies in obese ladies and in those with big uteri (up to 14-16 weeks size).

In case of laparoscopic hysterectomy, major complications were defined as complications requiring re-surgery on conversion to laparotomy. In a study a total of eight patients $(6.6 \%)$ required a laparotomy. ${ }^{24}$ Other study ( $\mathrm{n}=252$ TLH cases) showed $1.59 \%$ of major complications..$^{25}$ In a two phase study by Wattiez et $\mathrm{al}^{20}$, there were substantial decreases in major complication rates from $5.6 \%$ to $1.3 \%$. Agarwal et $\mathrm{al}^{21}$ experienced incidence of major complications during TLH was $1.6 \%$ and rate of conversion to laparotomy was $9.7 \%$.

Conversion to abdominal hysterectomy was unavoidable (with $1.15 \%$ conversion rate). ${ }^{18}$ Wattiez et al20 noticed such conversions $4.7 \%$ and $1.4 \%$ in the period of 1989-1995 and 1996-1999 respectively. Terzi et $\mathrm{al}^{26}$ studied conversion rate in three groups and found conversion rate of $6.67 \%$ in first group, $5.33 \%$ in the early group and $0.93 \%$ in the final group. Park $\mathrm{SH}$ et $\mathrm{al}^{27}$ noticed the rate of conversion to laparotomy was $8 \%$ with independent risk factors for conversion were adhesion and uterine weight. Of the 261 laparoscopic hysterectomies, 8 cases $(3.07 \%)$ turned into open in our study. Fibroid (five cases), dermoid cyst (two cases) and grade IV endometriosis (one case) were the reasons for turning into laparotomy. As a major complication, one case required re-laparotomy for pelvic hematoma following LAVH and another case required ureteric injury repair following TLH. Other minor complications were requirement of blood transfusion (at most three pints), spotting per vaginum, port site infection and hematoma but the numbers were very few.

\section{CONCLUSIONS}

Laparoscopic hysterectomies are feasible and can be performed in a tertiary level hospital. We have reduced our mean operating time across the study period despite limited resources and the increasing complexity of cases. These minimal invasive surgeries are safe with low rate of complications and less conversion to open even in our set up.

\section{ACKNOWLEDGEMENTS}

The authors would like to thank Dr Sunila Shakya and entire laparoscopic surgeons and operation team of KUH.

\section{CONFLICT OF INTEREST}

No conflict of interest was declared by the authors.

4. Subramonian K, Muir G. The "learning curve" in surgery: what is it, how do we measure it and can we influence it? BJU Int. 2004:93(9):1173-4.

5. Rosen DM, Cario GM, Carlton MA, Lam AM, Chapman M An assessment of the learning curve for laparoscopic and total laparoscopic hysterectomy. Gynaecol Endosc. 1998;6:289-93

6. Padhye SM. Experience of laparoscopic sterilization under local anesthesia in camps in Nepal. J Inst Med. 1984;(6):31-6.

7. Saha R, Shrestha NS, Thapa M, Shrestha J, Bajracharya J, Karki SC. Experiences of gynecological laparoscopic surgeries in a teaching hospital. J Nepal Health Res Counc 2013;11(23);49-52. 
8. Bajracharya N, Dangal G, Karki A, Pradhan H, Shrestha R, Bhattachan K, Poudel R. Experience of Laparoscopic Gynecological Surgeries at Kathmandu Model Hospital. NJOG. 2017;23(1):22-5.

9. Reich H, DiCaprio J, McGlynn F. Laparoscopic hysterectomy. J Gynecol Surg. 1989;5:213-6.

10. Yu LH, Shrestha R. Comparison between Laparoscopic Hysterectomy and Abdominal Hysterectomy. NJOG 2014;9(1):26-8. ISSN 1999-8546. Available at: <http://njog. org.np/njog/index.php/njog/article/view/77>

11. Hunter, EK. Evidence-based implementation and increase in the rate of laparoscopic hysterectomy. Aust N Z J Obstet Gynaecol. 2015;55(2):112-5. DOI:: 10.1111/ajo.12280. Epub 2014 Dec 24.

12. CDC-MMWR: Hysterectomy surveillance United States, 1994-1999. July 12, 2002/51 (SS05);1-8

13. Farquhar CM, Steiner CA. Hysterectomy rates in the United States 1990-1997. Obstet Gynecol. 2002;99:229-34.

14. Englund M, Robson S. Why has the acceptance of laparoscopic hysterectomy been slow? Results of an anonymous survey of Australian gynecologists. J Minim Invasive Gynecol. 2007; 14:724-8.

15. Rouzier R, Pomel C. Update on the role of laparoscopy in the treatment of gynaecological malignancy. Curr Opin Obstet Gynecol. 2005; 17:77-82

16. Harkki-Siren P, Sjoberg J, Makinen J. Finnish national register of laparoscopic hysterectomies: A review and complications of 1165 operations. Am J Obstet Gynecol. 1997;176:118-22.

17. Leminen A. Comparison between personal learning curves for abdominal and laparoscopic hysterectomy. Acta Obstet Gynecol Scand. 2000;79:1100-4.

18. Shwayder JM. The Learning Curve for Laparoscopically Assisted Vaginal Hysterectomy/Laparoscopic Hysterectomy. J Am Assoc Gynecol Laparosc. 1994;1(4):S33.
19. Mavrova R, Radosa JC, Wagenpfeil G, Hamza A, Solomayer EF, Juhasz-Böss I. Learning curves for laparoscopic hysterectomy after implementation of minimally invasive surgery. Int J Gynaecol Obstet 2016;134(2):225-30.

20. Wattiez A, Soriano D, Cohen SB, Nervo P, Canis M, Botchorishvili R, et al. The learning curve of total laparoscopic hysterectomy: comparative analysis of 1647 cases. J Am Assoc Gynecol Laparosc. 2002;9(3):339-45.

21. Agarwal P, Bindal N, Yadav R. Risks and Benefits of Total Laparoscopic Hysterectomy and the Effect of Learning Curve on Them. J Obstet Gynaecol India. 2016;66(5):379-84. DOI: 10.1007/s13224-015-0706-9. Epub 2015 Jun 11.

22. Ren TLC, Kannaiah K. A review of clinical benefits of tota laparoscopic hysterectomy and total abdominal hysterectomy. Sungai Petani: Hospital sultan Abdul Halim; 2010.

23. Tomov S, Gorchev G, Tzvetkov Ch, Tanchev L, Iliev S. Laparoscopic hysterectomy--brief history, frequency, indications and contraindications. Akush Ginekol (Sofiia). 2012;51(4):40-4

24. Garrett AJ, Nascimento MC, Nicklin JL, Perrin LC, Obermair A. Total laparoscopic hysterectomy: the Brisbane learning curve. Aust N Z J Obstet Gynaecol. 2007;47(1):65-9. DOI: 10.1111/j.1479-828X.2006.00682.x.

25. Donnez O, Donnez J. A series of 400 laparoscopic hysterectomies for benign disease: a single centre, single surgeon prospective study of complications confirming previous retrospective study. BJOG. 2010;117(6):752-5. DOI:: 10.1111/j.1471-0528.2010.02520.x. Epub 2010 Feb 22

26. Terzi H, Biler A, Demirtas O, Guler OT, Peker N, Kale A Total laparoscopic hysterectomy: Analysis of the surgical learning curve in benign conditions. Int J Surg. 2016;35:51-7. DOI:: 10.1016/j.ijsu.2016.09.010. Epub 2016 Sep 12

27. Park SH, Cho HY, Kim HB. Factors determining conversion to laparotomy in patients undergoing total laparoscopic hysterectomy. Gynecol Obstet Invest. 2011;71(3):193-7. DOI:: 10.1159/000317520. Epub 2010 Dec 15 